mediastudies.press • Social Media \& the Self: An Open Reader

\title{
Gendered Visibility on Social Media: Navigating Instagram's Authenticity Bind
}

Brooke Erin Duffy ${ }^{1}$, Emily Hund ${ }^{2}$

${ }^{1}$ Cornell University, ${ }^{2}$ University of Pennsylvania

Published on: Sep 22, 2019

License: Creative Commons Attribution-NonCommercial-NoDerivatives 4.0 International License (CC-BY-NC-ND 4.0). 


\section{ABSTRACT}

Although the digital economy's guiding logics of attention and visibility rouse social media users to put themselves out there, individuals experience digital visibility in profoundly uneven ways. For women, in particular, the public nature of online communication is fraught with risk, opening the potential for ridicule, hate, and harassment. This research explores the vexed nature of visibility among Instagram content creators, a community that is especially beholden to this so-called "visibility mandate." Drawing on in-depth interviews with 25 aspiring and professional Instagrammers, we show how they attempt to stave off potential critique in patterned ways. In their efforts to project themselves as authentic, many sought to deflect accusations of being too real, and, alternatively, as being not real enough. We argue that this uniquely gendered form of a socially mediated "authenticity bind" indexes the wider policing of women and other marginalized communities in digitally networked spaces, wherein they must carefully toe the line between visibility and vulnerability.

Keywords: social media, visibility, gender, authenticity, Instagram, influencer

GUIDED BY THE social media economy's logics of attention and reputation, Internet users are roused to pursue markers of visibility in the form of likes, favorites, comments, and retweets. $\underline{1}$ On the surface, at least, it seems the greater one's visibility, the better; careers are borne, new social connections forged, and opportunities for status and professional success abound (e.g., (Abidin, 2016; Banet-Weiser, 2012; Cotter, 2018; Duffy, 2017; Marwick, 2013; Schaefer, 2012). Crucially, however, individuals experience digital visibility in staggeringly uneven ways. For marginalized communities, in particular, the act of communicating in public is fraught with risk and includes the potential for criticism, hate, and harassment. Perhaps unsurprisingly, experiences of online harassment often map onto axes of social identity, including gender, sexuality, race, age, and class. According to a U.S. survey published by the Pew Research Center, roughly a quarter of African Americans and one in 10 Hispanics have been the target of racial/ethnic harassment, compared with just 3\% of Whites (Duggan, 2017). The study also found that women are nearly twice as likely as men to say they have experienced gender-based harassment.

Against this backdrop, both academic research and accounts from popular culture have drawn much-needed attention to the risks of online visibility for women 
occupying certain professional sectors. This includes those whose careers demand a high degree of social media publicness, including journalists (Eckert, 2018; Usher, Holcomb, \& Littman, 2018), political leaders and activists (Banet-Weiser, 2018; Dreyfuss, 2018; Nakamura, 2015), creative entrepreneurs (Duffy \& Pruchniewska, 2017), and academics (Chess \& Shaw, 2015; Veletsianos, Houlden, Hodson, \& Gosse, 2018). A 2018 Amnesty International report, which drew on crowd-sourced data from more than 700 women journalists and politicians across the United States and United Kingdom, revealed the extent of misogyny on one particular platform: Twitter. Among the findings were that $7.1 \%$ of tweets to female public figures were "abusive or problematic" and, moreover, "black women were $84 \%$ more likely to be targets of abusive tweets than white women" (Dreyfus, 2018, para. 4). As the senior adviser for tactical research at Amnesty International summarized, "We have the data to back up what women have long been telling us-that Twitter is a place where racism, misogyny and homophobia are allowed to flourish basically unchecked" (para. 3).

Professionals with careers borne by social media, such as YouTube vloggers, bloggers, and Instagrammers, ostensibly experience the demands of what we call the "visibility mandate" - that is, the directive to "put oneself out there"-to a heightened degree. Indeed, their career success is directly hitched to data-driven metrics (i.e., likes, followers, and comments) that make influence and status legible to both advertisers and audiences. At the same time, such visibility makes them susceptible to public surveillance and its consequent risks (e.g., Banet-Weiser, 2012, 2018; Duffy \& Pruchniewska, 2017; Nakamura, 2015).

The role of social media platforms in enabling networked hate and harassment has been brought into stark relief in recent years. Yet, much of the research and policy debates center on Twitter, YouTube, and Facebook; thus, Instagram-the visually oriented social networking site recognized as a central vector for commerce and cultural production-remains ripe for scholarly analysis. In the popular imagination, at least, Instagram-with a user experience focused on curated images and, increasingly, opportunities to shop-furnishes its user base with a comfortable space for participation, a testament to what Lorenz (2018) describes as the site's "long-standing and well-crafted reputation for being the nicest place on the internet" (para. 6). It is precisely because of this reputation that the harassment that takes place on the platform-along with the attendant implications for content creators-is characteristically dismissed. Indeed, as is so often the case, spaces understood to be the domain of consumerism and social connection-domains often coded as feminine- 
fail to register the levels of critical assessment granted to traditionally masculine topics (Levine, 2015).

In response, this article explores how Instagram's aspiring and professional content creators - colloquially known as "influencers" and overwhelmingly comprised of women-navigate the demands of digital visibility. Empirically, we draw on in-depth interviews with 25 fashion, beauty, and lifestyle Instagrammers to show how their online activities are routinely structured in anticipation of critical feedback and policing. More specifically, we found that interviewees exhibited concern with projecting themselves as "not real enough" or, alternatively, as "too real." By drawing attention to the gendered experiences of the so-called "authenticity bind"-which Pooley (2010) identifies as the plight to reconcile "self-promotion and expressive distinction" on social media (p. 72)-we show how normative conventions of feminine self-presentation hem in content creators' activities in patterned ways. More broadly, we argue that Instagram's authenticity bind indexes the wider policing of women and other marginalized populations in digitally networked spaces, where they must carefully toe the line between visibility and vulnerability.

\section{Visibility in the Social Media Age}

The concept of visibility is both profoundly vexed and highly politicized, a fact made all the more evident in mediated contexts. More than a decade ago, Thompson (2005) highlighted the reconfigured nature of visibility amid a wider media environment

where the field of vision is no longer constrained by the spatial and temporal properties of the here and now but is shaped, instead, by the distinctive properties of communication media, by a range of social and technical considerations (such as camera angles, editing processes and organizational interests and priorities) and by the new types of interaction that these media make possible. (pp. 35-36)

In the political realm, Thompson explained, mediated visibility amounts to a "doubleedge sword" by providing once-restricted information and imagery to the masses while also subjecting public figures to intensified scrutiny (p. 41). Today's visibility mandate, by contrast, has a less collective-and decidedly more entrepreneurial-valance (BanetWeiser, 2018). Accordingly, visibility has been widely touted as a key affordance of social media platforms such as Facebook, Instagram, and YouTube (e.g., Abidin, 2016; Bishop, 2018; Cotter, 2018; Duffy, 2017). By prodding users to put themselves out there, these social networks cast visibility as a route to social connectivity, career 
windfall, and other positive returns. The digital advertising economy that propels these sites, moreover, constructs visibility in an unabashedly data-driven way by financially incentivizing indexes of attention and reputation (Gandini, 2016; Hearn, 2010). Unfortunately, the economic returns on digital visibility seem to be unevenly distributed across gender lines (Duffy, 2017) and, moreover, tend to reaffirm traditional social roles and norms. As Bishop (2018) argues of YouTubers' pursuit of visibility, "the algorithm privileges and rewards feminized content deeply entwined with consumption, beauty, fashion, baking, friendships and boyfriends in the vein of the historical bedroom culture of the teenage magazine” (p. 70).

As studies of YouTubers, Instagram influencers, and other social media content creators make clear, the last decade has witnessed the emergence of new celebrityexemplars whose success hinges on networked visibility (e.g., Abidin, 2016; Duffy \& Hund, 2015; Hearn \& Schoenhoff, 2015; Khamis, Ang, \& Welling, 2017; Marwick, 2015; Senft, 2008. Yet, despite-or perhaps because of-the presumed intimacy of being "out there," the processes of managing, understanding, and acting on this visibility mandate can exact a cost. As Abidin (2016) shows, influencers are compelled to engage in "visibility labor," devoting time and energy to their "self-presentations so as to be noticeable and positively prominent among prospective employers, clients, followers and fans" (p. 5).

The concept of visibility labor dovetails with other forms of immaterial labor that are increasingly framed as requirements of the neoliberal attention economy. Marwick (2013), for instance, illustrates how white-collar tech workers internalized the directive to be active on sites like Twitter; a key element of burnishing their personal brands, she explains, is ensuring that such images are rendered visible (p. 93). Duffy (2017), meanwhile, notes how young women are encouraged to invest time, energy, and even capital in their online personae as an ostensible "reprise of the female body's visibility in twentieth-century consumer culture" (p. 10). Accordingly, the labor of visibility offers different rewards and risks depending on who undertakes it and to what ends. In theorizing what she calls the gendered "economies of visibility" that have supplanted collective representational politics, Banet-Weiser (2018) draws attention to patterned disparities whereby "the product . . . is the body (most often the bodies of heteronormative, cis- gendered women). Its value is constantly deliberated over, surveilled, evaluated, judged, and scrutinized through media discourses, law, and policy" (p. 28). Banet-Weiser's invocations of surveillance, judgment, and scrutiny are a testament to the extent to which socially mediated visibility coincides with a heightened degree of vulnerability. 


\section{Online Vulnerability: Policing and Harassment}

Despite the assurances of success that can befall those who put themselves out there, the experience of being visible is burdened by risks of varying degrees and kind.

Identity policing, for one, runs rampant in digital spaces as various subcultures seek to delineate the contours of their respective groups (Reagle, 2015). In male-dominated communities and cultures-such as tech, gaming, and sports- enactments of group membership routinely invoke gender codes and norms (Banet-Weiser, 2018; Nakamura, 2015; Reagle, 2015; Salter \& Blodgett, 2017). Reagle’s (2015) analysis of the "fake geek girls" discourse, for instance, draws attention to the ways in which women trying to make inroads into geek cultures get cast as "outsiders." The particular quandary they face amounts to what Reagle describes as a double bind: “between being too geeky and not geeky enough" (p. 2866).

A more acute risk of online visibility for marginalized populations is exposure to hate and harassment. The psychological impact of such expressions of networked hate are profound, with women reporting a higher degree of distress in response to harassment, a telling signal that "their experiences are particularly insidious and likely qualitatively different than those of men" (Fox, Cruz, \& Lee, 2015, p. 436). Moreover, the potential for critical blowback has spurred users to engage in various kinds of selfpolicing (e.g., Cirucci, 2018; Eckert, 2018). Cirucci (2018), for instance, found that compared with men, women expressed a greater degree of reluctance posting certain types of content, based largely on the perceived response of their audience. The women in her study were thus especially self-reflective about social interactions, with many expressing fears of confrontation or disparagement (p. 2948).

Women in public-facing professions are especially susceptible to online critique and harassment, highlighting the extent to which visibility and vulnerability seem to rise in tandem. Although journalists of all stripes are expected to pursue visibility and engage in strategic self-promotion, women experience a disproportionate share of the public criticism (Eckert, 2018). In a particularly noteworthy example from 2016, feminist journalist Jessica Valenti took a public break from social media after she received rape and death threats directed at her young daughter (Piner, 2016). In the academy, meanwhile, as scholars are being counseled to communicate their findings to networked publics through digital and social media platforms, negativity and trolling are rife (Chess \& Shaw, 2015; Veletsianos et al., 2018). Women scholars thus feel compelled to engage in self-censorship, which has significant implications for both academic discourse and wider civic life (Veletsianos et al., 2018; Vera-Gray, 2017). As 
Sobieraj (2018) usefully contends to this end, "If women curtail their online participation as a result of harassment, the end result is likely a reduction in diversity of thought and opinion in the commons as well as within academia more generally" ( $p$. 4692).

The platforms on which networked communication take place consistently fail to provide content creators with adequate recourse. Instead, even extreme forms of critique have been normalized as an inevitable side effect of participation in digitally networked spaces. Summarizing the problems inherent in the lackluster structures of Internet governance, Eckert (2018) notes how "the Internet remains a space that is legally, technologically, socially, and culturally constructed to allow perpetrators of online abuse, misogyny, sexism, and racism to go largely unpunished" (p. 1286). Instagram, which as Lorenz (2018) points out, "has traded on its reputation as a place for positive, aspirational content-for shopping, connecting with friends, and following interests-" fell behind in addressing the types of negativity that increasingly flourish, with some employees arguing that the company's antiharassment initiatives were "understaffed and unprioritized" and "mostly done for PR" (Lorenz, 2018, paras. 1314).

The years without adequate safeguards-paired with Instagram's guiding logic that privileges aspirational self-expression and calculated attention-seeking (Marwick, 2015) -means that so-called influencers are especially susceptible to policing, abuse, and harassment. And, ostensibly, they experience particularly gendered expressions of such hate. The website Get Off My Internets (GOMI), which launched in 2009 and was later dubbed the "Craziest Destination for Blogger Hate" (Lieber, 2014), is perhaps the best known repository for such criticism (MacRae, 2017). A key subject of contestation on the site is around competing notions of authenticity. GOMI forums, explains McRae (2017), target posts that the community deems "staged, insincere, unethical, and exaggerated" (p. 14). Of course, these gendered criticisms of fakery are not without precedent; rather, they seem evocative of longstanding patriarchal fears that women will disguise their "authentic" selves with tools of artifice and deception. $\underline{2}$

\section{Authenticity Demands in the Age of Instagram}

Appeals to authenticity are deeply structured into the ethos of Silicon Valley (e.g., Gehl, 2011; Marwick, 2013; F. Turner, 2010), with individual social networks invoking ideals of sincere expression and realness as bulwarks against competing platforms (Salisbury \& Pooley, 2017). Content creators, meanwhile, are expected to project 
themselves authentically while carefully adhering to the tenets of online self-branding (e.g., Abidin, 2016; Cunningham \& Craig, 2017; Duffy, 2017). Oxymoronic phrases such as "calibrated amateurism" (Abidin, 2016), "calculated authenticity" (Pooley, 2010), "curated imperfection" (L. Turner, 2018), and "aspirational ordinariness" (MacRae, 2017) highlight the oft-strategic deployment of these appeals. Social media audiences, meanwhile, increasingly engage in what amounts to authenticity policing, in which they call out individuals who seem to defy norms of authentic selfpresentation. In some cases, communities of antifans (including, but not limited to, GOMI and Guru Gossip) have sprung up to publicly critique the inauthentic displays of highly visible personae (MacRae, 2017; Miltner, 2016).

On Instagram, authenticity has been fiercely contested from the outset. In the wake of its launch in 2010, the site's photo filter offerings sparked concerns about a fauxnostalgia aesthetic (Halpern \& Humphreys, 2016, p. 73). More recently, as the app has popularized and become integral to the digital advertising economy, high-status users' portrayals of their \#blessed lifestyles-from photos of exotic travels and curated fashions to latte art and \#foodporn-have drawn mocking critique. By some accounts, we have now entered a postauthenticity age (Owens, 2018); yet, authenticity remains a meaningful ideal on social media. How, then, do participants negotiate the demands of visibility and vulnerability, especially when their socially mediated projections of authenticity are so carefully scrutinized by networked audiences? And in what ways are these negotiations implicated in gender norms and expectations?

\section{Method}

Data for this project came from in-depth interviews with aspiring and professional Instagram content creators located throughout the United States and Canada. Participants were recruited on Instagram, using popular influencer hashtags to develop a list of potential recruits who (1) posted content regularly across popular genres of Instagram production (including travel, fashion, beauty, parenting, fitness, and lifestyle), (2) included their e-mail addresses in their Instagram or blog bio, and (3) appeared, through their display of sponsored content, to earn some remuneration for their work. We contacted approximately 200 people via e-mail, explaining our identities as university researchers, the contours of the project, and asking them to participate in an in-depth interview with one of us or a trained research assistant. Given a larger concern with exploitation in the social media field (Duffy, 2017), we offered participants a payment of $\$ 20$ (gift card or PayPal) in exchange for their time and insight. 
Although we sought to recruit a diverse pool of participants across professional, personal, and geographic contexts, it is important to qualify that the demographic makeup of our sample was limited by the narrow culture of influencers (see, for instance, Carah \& Dobson, 2016; Duffy \& Hund, 2015), as well as by the gender disparity of Instagram users, in which women are a notable majority (Anderson, 2015). Despite our efforts, our interview sample included only one man. As such, we acknowledge that the gendered framework of our study is not comparatively based (i.e., men vs. women) but, instead, reflects an ostensible "cultural feminization" (Adkins, 2001) of the field of social media production. In addition, we faced a difficult balance between addressing participants' desire for visibility and the vulnerability of online research. $\underline{3}$ Thus, we opted to anonymize all interviewees.

Interviews were conducted until, through our frequent discussion and review, we determined that theoretical saturation had been reached (Glaser \& Strauss, 1967). In total, 25 interviews were completed in 2017-2018. The majority of these interviews were conducted over the phone and lasted between 15 minutes to more than an hour. Interviews were transcribed using a professional transcription service, and we used an interactive, inductive approach to develop coding categories. To code the data, we followed a grounded theory approach, which involves linking "analysis and data collection that uses a systematically applied set of methods to generate an inductive theory about a substantive area" (Glaser, 1992, p. 16).

\section{Findings: A Gendered "Authenticity Bind"}

In a cultural moment when authenticity remains a resonant-albeit confoundingideal, it is perhaps not surprising that social media users' activities are structured by a command to project themselves as "real." But many of our interviewees-as highly visible content creators facing intensified scrutiny and policing-took considerable measures to stay within the perceived boundaries of this authenticity ideal. More specifically, we learned that their creative and promotional activities were shaped by two competing demands: a desire to present themselves as real enough without stepping into territory that could be perceived as too real. Navigating these evershifting limitations - trapped in a gendered sort of authenticity bind (Pooley, 2010)_ was articulated as a way to burnish one's image while simultaneously deflecting potential critique. Interviewees reported that being perceived as either too real or not real enough would generate negative blowback that could impact them emotionally and/or financially. 
Before discussing how content creators sought to operate within these imagined boundaries around authentic self-performance, it seems important to address how our interviewees understand Instagram's alleged "visibility mandate." Roused by the social media economy's demand to put themselves out there, many responded in turn by sharing intimate moments of their lives with socially networked audiences. Constance, for instance, explained that she feels a need to communicate "personal stuff" and "share things . . . in my life." In the same vein, Sasha noted how she posts "little behind the scenes [images] of, me and my kids and stuff . . . people like seeing like real things." These quotes echo findings from Duffy and Pruchniewska's (2017) study of independently employed women cultural workers; while scouting gigs, they feel compelled to "make their personal lives visible" by displaying feminine-coded images and aesthetics. Mia, meanwhile, mused that social media platforms sought to exploit a fundamental element of human nature, namely attention:

Then comes along Instagram, [which] said, "Hey, not only can you validate yourself by sharing it with your friends, but you can do it by sharing it with strangers." It's really just, we . . require an audience. The simplicity and the aesthetic beauty of what Instagram allows . . . how can you resist?

Other interviewees expressed some ambivalence about the particular affordances and aesthetics associated with Instagram visibility. Riley, for instance, struggled to adapt to the site's Stories feature, which the platform introduced in 2016 in a not-so-subtle imitation of Snapchat. Whereas advertisers quickly came to view Instagram Stories as a crucial tool for influencers' promotional messaging (Fleck, 2018), not everyone enjoyed the narrative format. As Riley explained, "I personally am not one that is super comfortable talking to my front-facing camera on Instagram Stories yet I feel really awkward." Others expressed unease about the narrow ways in which visibility plays out, including the pressure they experience to "look the part" (Wissinger, 2015). As lifestyle blogger Janie admitted, “If I'm not wearing makeup, I'm not going to post [an image of myself]."

Notably, however, several interviewees acknowledged a desire to break from the visibility demands they experience, especially those deemed excessively curated. As Helene confessed,

It kind of has taken a toll on me, and I think that's why I'm naturally backing away from Instagram, without even realizing it, because I'm kind of getting sick of trying to make my life always look [a certain way]. It's a lot of effort when it's kind 
of not who I really am as a person. So, I feel myself naturally backing off of it, just because I realize how it can be unhealthy for me.

Sasha, too, found the performative dimensions of Instagram "stressful," in part because "sometimes people are really negative on social media." Her belief, by contrast, was that "everyone on social media should be nice."

To this end, a number of our interviewees articulated their own efforts to challenge the culture of negativity. As Elise said,

I don't wanna drive a political debate or controversy with people. That's not what this is platform is about. This platform for me is about encouraging and motivating people to live the most joyful, full life they can live; I think I always go back to that.

Or, as Carrie put it, she wants to "make [Instagram] a positive place." As she reasoned, "Instagram has just become this weird platform where people use it as their business, and it is very creative, [and] it makes other people feel bad." She added,

There's obviously lots of cyber-bulling going on and there's lots of negativity going on. So, I think you just have to be smart about how you use it, because it has changed a lot and it really just does affect people's lives.

As Carrie's comment makes clear, strategic behavior-or "being smart" - is seemingly required to navigate the fraught nature of visibility on Instagram.

\section{Projecting Authenticity: Being "Real Enough"}

Reflections on the contested notion of "authenticity" revealed content creators' awareness of the potential feedback and policing their online activities could elicit. Many, consequently, sought to distance themselves from so-called fakery in patterned ways. Sasha, for instance, detailed the ascent of a social media-borne faction contending that "bloggers aren't real. Bloggers are fake." On Instagram, she explained, content creators are often criticized for "making women feel bad about themselves because [audiences] can't afford [their lifestyles]." In response, Sasha tried to inject moments of candor and relatability into her online presence by, for example, showcasing candid photos rather than those she deemed "too posey." Helene, meanwhile, described an increasing pressure for all Instagram users to "keep it real" amid the wider cultural backlash against the curated, filtered depictions that seem to dominate the app. She detailed a perception that social media users want "Instagrammers to show their messy kitchens every once in a while, or their messy 
living room when their toddler just destroyed it. Like, [people want us to] quit showing everything so perfect, I guess."

Libby, similarly, noted a desire to present herself as "approachable": "I think that comes back to the biggest thing . . . which is authenticity," she said. "It's a big turn off if you come across as fake." As Libby explained of social media audiences' perceived desire for realness, "People don't want to know robots, they don't just want to know the screen, they kind of want to know the people behind the screen." After this Goffman-esque backstage reference, Libby described what she understood as a pervasive sentiment on social media wherein "humans starve for relationships":

I've noticed just looking at the analytics of my posts that when you post things personal . . or your family, or what's going on in your life, or lessons that you've learned, or trials you're going through-those posts actually do probably $50 \%$ better than any of the other posts. So . . . it's something that I definitely do, because, one, not only does it help other people who might be going through something similar, but [also because] the post themselves do a lot better and reach more people.

Libby's commitment to sharing personal moments is not unlike the "confessional" ethos that structures reality TV performances, "reinforce[ing] the idea that the production of closeness and the public display of once-private feelings are intrinsically gendered activities" (Genz, 2015, p. 553). Notably, Libby framed her authentic selfexpressions as a boon to her social media brand (e.g., doing "better" and "reach"), in addition to functioning as a mechanism for social support.

Other content creators, meanwhile, espoused the social media axiom of consistency, whereby "being real" is projected through perceived congruity between one's online and offline personae (e.g., Gershon, 2017; Marwick, 2013). Olivia, a fitness Instagrammer, recalled her first in-person meeting with someone in her digital network, who told her, "You're exactly like your Instagram is." She explained, "That stuck with me and . . . because that's my goal is actually to not create an Instagram self I don't know, like, I want it to be a reflection of me, not a fake reality version of me."

This sort of perceptive distancing from anything deemed "fake" was a common refrain among our interview participants. Setting herself apart from the imagined category of other content creators, Alana offered, 
I try not to portray myself as, "I'm a fashionista, look what I'm wearing." Because I feel I'm not the most stylish person ever. I mean, I sometimes have really good outfits, but I don't see myself as a fashion person. I see myself as a storyteller. [I'm] this awkward girl who grew up and became something.

By invoking "awkward[ness]" and storytelling rather than mere aesthetics, Alana is able to provide herself not only with a guiding logic for creating a cohesive Instagram presence, but also personal meaning. Indeed, it is important to note that many influencers we interviewed expressed an appreciation for the sense of control they are able to exert in the production of their online personae, a finding that aligns with other research (e.g., Hund \& McGuigan, 2019). Helene's self-assessment is strikingly similar in its conflation of self-branding and inner-driven authenticity:

I am a small town girl. I will never be that person who's living in L.A., or New York City, or Chicago. So I just try to keep it real for those that follow me, that I'm more of the relatable blogger that you'll come across and I've kind of found that, that works for me, being true to myself works for me, instead of trying to be someone I'm not.

Despite such narrativizations of the self, the reality of online self-presentation practices is that, much like offline, individuals do vary their projections of self based on the particular audience and social context (boyd, 2014; Gershon, 2017; Scolere, Pruchniewska, \& Duffy, 2018; van Dijck, 2013). It is in this vein that our interviewees use the particular affordances of Instagram-including the multiple accounts feature and Instagram Stories - to uphold this ideal of "being real." The multiple account phenomenon on Instagram is distinctive from the (in)famous "one identity" policy of Facebook, which of course owns the former (van Dijck, 2013). That is, Instagram allows users to easily toggle back and forth between accounts to manage different selfpresentations. This affordance underpins the rise of "finstas," or the "fake" Instagram accounts that users set up as distinctive from their "real" accounts in order to share different types of content (Duffy \& Chan, 2019). Karly thus explained how her "finsta" enables her to share content with a more intimate audience, granting her the flexibility to present images that do not fit squarely with her personal brand.

Other interviewees, meanwhile, lauded Instagram's ephemeral Stories feature for allowing them to project mundane realness without disrupting the digital self-branded personae they had so carefully created on their static feeds. One Instagrammer praised Stories for this very reason, noting her belief that "everyone nowadays just really likes to see what's real and what's going on in the moment." Instagram, she 
continued, "really hit the nail on the head adding that feature because you can have a picture-perfect life on your Instagram feed, but you can have your real life on your Instagram Story." Sasha's understanding of the dichotomy between Instagram's visual and narrative elements was remarkably similar; her description of showing herself "without makeup" also reflects longstanding moral framing of cosmetics as aids of feminine deception (Peiss, 2011):

Your Instagram posts are always just kind of perfect, I feel like. And then your stories are kind of like real life. Like people want to see, you know, things that are real ... there's a huge debate over this, but bloggers aren't being very real on Instagram, everything's just like too perfect I guess. So I did an Instagram story the other day, and I was like, no makeup on, like chilling in my bed with the baby and talking about keeping it real or something. And I got so much feedback on that, like people wanted to see me without makeup, or without my hair perfect.

Another one of our interviewees articulated Instagram's Stories as "a good way to show people your personality." She reasoned, "Everyone out there has similar content, to some extent, but . . . your followers and your readers get to know you through your personal stories." Here, authenticity discourses are valued for their ability to aptly project one's distinctive brand persona (Gehl, 2011; Pooley, 2010).

To this end, content creators also sought to be "real enough" with regards to the brands with which they decided to partner. After all, influencer marketing is predicated on the assumption that brand ambassadors only hype products they really love, lest they be accused of "selling out" (Duffy, 2017; MacRae, 2017). Constance, for instance, said she limits sponsored content in her feed to deflect accusations of crass commercialism: "I try to keep eighty to ninety percent of my posts real, authentic, organic. And maybe 10\%-20\% maximum, I post things [where] . . you can tell it's an ad." Commenting on the potential for backlash, she continued,

Because I don't want anyone to ever look at my feed and be like, “Oh, this girl does nothing but just promote things so she probably doesn't even really like them." And I think that's the worry that is coming out [the Instagram community in response to] . . . influencers like, "Oh, did they actually really like this product, or are they just being paid?"

Anne, meanwhile, invoked the ideal of relatability in describing her overall approach to content creation: "You have to post what's happening in your life so that your feed is not all ads." 
Finally, several of our interviewees noted how they felt bound by their public histories on the app, which-intentionally or not-create an online chronicle visible to audiences. Their past posting activities, in other words, function as what Humphreys (2018) describes as traces, which "indicate [one's] presence, existence or action through media” (p. 9). As Riley noted, “Once you've built that brand persona and that aesthetic that people are used to seeing, when they see something that kind of falls outside of that line, they might either think it's forced or not authentic." She continued,

And so that's really the battle there, in terms of if you want to build that aesthetic and that feed, then by all means, do it. But then if you kind of deter from that for any reason in an unnatural way, then it can kind of look a little bit forced.

Such accounts reveal how content creators use Instagram's "authenticity affordances" to inject more "realness" into their creative products, without detracting from the brand-centric ethos structuring their curated feeds. As we show next, however, attempts to provide "authentic" self-presentation on Instagram were also guided by a concern with the network's pervasive "call-out culture."

\section{Deflecting Critique: Avoiding Becoming "Too Real"}

Although there are discernible social and economic benefits to showcasing one's "realness" on Instagram-from amassing a dedicated following to appealing to potential brand sponsors-interviewees outlined the recurrent possibility of being perceived as "too real." Indeed, a number of our interviewees explained how they were beholden to the Instagram community's unwritten and ever-shifting codes of "realness." As Molly shared,

There's this whole thing right now about how influencers or bloggers . . they don't show real motherhood. But at the same time, if I posted a picture of my dirty restroom, like, would anyone like that? Would anyone want to see that? You know, I don't think so. I think even people that are not influencers-on a personal level, do you post, "Got in a huge fight with my husband last night!" No! No one does that!

Helene, similarly, noted how her efforts to showcase a realistic domestic life are still constrained by rather traditional impression-management tactics:

I do think that, you know, maybe people do want to see you have a messy kitchen every once in a while. It's just strange, though. What do you do when someone comes to your house? You clean it up, don't you? [Posting on Instagram] is almost 
like you're having company over. You just don't think to have your makeup everywhere, and your house kind of crazy.

As the accounts of Molly and Helene make clear, Instagrammers' desire to project an image of "realness" are reined in by their understandings of social media selfpresentation.

Libby, meanwhile, shared concern about how expressions of unabashed candor, particularly those that defy archetypical notions of femininity, could adversely impact her social media metrics. Describing the tension she feels to produce an image that's simultaneously "perfect" and "off the cuff," Libby explained, "It's like, people want something real, but at the same time they don't." She went on to describe the potential impact on her follower count:

You're in this conundrum where you wanna be a little bit more real, but if you start posting anything that's not elevated and inspirational/aspirational, people unfollow you because [they think], “Oh, this isn't pretty. I wanna follow something pretty."

Not only did Instagrammers explain how posting less-than-perfect images could put their careers at risk, they also discussed the possibility for public critique and/or networked hate. Constance shared,

I think as my account has grown and you have so many people following you, you open yourself up for ridicule and criticism. And, there's also obviously a ton of supporters and a ton of positivity, but then there are those few people, obviously, that are kind of there to knock you down a few pegs.

Mia, similarly, explained, "If somebody care[s] enough to say something bad to you about the stuff you've posted, you know you've gotten their attention." She recalled, "[When] it did happen to me, I thought, 'Well, I have arrived.'” As the appraisals of Constance and Mia make clear, the cost of increased visibility is oftentimes a heightened degree of vulnerability.

To avoid traversing into territory deemed overly real, interviewees engaged in various modes of self-censorship. The most obvious defensive act, as characterized by interviewees, was a basic filtering out of anything they believe could be perceived as objectionable by family, friends, or potential employers. Accordingly, interviewees cited photographs that show them drinking alcohol, wearing revealing clothing, or using profanity-even if these activities are regular parts of their lives-as "too real" for 
Instagram. "I wouldn't post anything I didn't want my mother [or] my grandmother to see," said Yasmin. There is also a sense that they would undergo preemptive vetting by professional contacts, including people who could refer them to jobs as well as brands that might want to sponsor their Instagram activities (echoing findings by Duffy \& Chan, 2019. As Riley explained of her filtering tactics:

It's kind of . . . censorship, I guess you could say, which sounds probably really bad when it's coming out of my mouth. But, when you're sending your profiles to be used by brands or companies or something like that, there's a lot of eyes on thatwhether PR agencies are looking at it, whether your grandma or grandpa or aunts and uncles are looking at it. So, I always try to keep a degree of professionalism.

It is perhaps not surprising that social media users sought to avoid posting images that could cast them in a negative light. Importantly, however, interviewees' reasons for doing so tended to reflect gendered norms of appropriate conduct, including those surrounding motherhood, domestic life, and beauty. Some, for instance, described a constant threat of being judged or even attacked by friends and strangers alike. "Say, for example, my son is standing in a shopping cart . . . I will not take a picture of that. I don't want to reflect that to other parents [who could critique me]," Janie said. To prevent criticism, users tended to craft Instagram posts with a positive, sometimes generic, spin. As Constance explained,

I feel like I had to learn to almost censor myself more, and back off from what I share. Not as to offend people, but almost to protect myself a little bit more, because people can be very critical and very opinionated when you put out your genuine, true thoughts. So, you almost have to put things out there that are a little bit more . . . not vague, but, just general, I guess you could say, rather than personal. . . . So, basically what my account has become now is sharing my blog posts daily and then little things here and there. . . . Whereas before, I was more open to share about my daily struggle or . . something more personal in my life.

As such comments make clear, Instagrammers worried that excessive "realness"especially when it diverges from feminine beauty ideals-could be detrimental personally and/or professionally.

\section{Conclusion: “You Haven't Really Made It 'til You've Been Hated On”}

Visibility is a resonant, even romanticized, ideal of the social media age, one championed by marketers, exhorted by entrepreneurs, and peddled by the 
mouthpieces of Silicon Valley platforms. Indeed, to be visible in a neoliberal attention economy is, above all, to be rendered valuable (Gandini, 2016; Hearn, 2010; Marwick, 2013). Yet, despite the upbeat framing of visibility in wider discourses of status and reputation, individuals experience the demand for online publicness in profoundly lopsided ways. For some, visibility is a conduit to success or even progressive social politics; for others-especially marginalized groups-it is tantamount to surveillance, as these individuals are subjected to intensified public scrutiny (e.g., Banet-Weiser, 2018; Dobson, 2016; Duffy, 2017).

In the case of our female interview participants, concerns about the negative implications of social media visibility-be it the emotional burden of patterned exposure to hate and harassment, or the financial costs associated with disappointing audiences or advertisers-were made legible in discussions about realness. In their efforts to project themselves as authentic, Instagrammers sought to deflect accusations of being "too real," and, alternatively, as being "not real enough." Imaginations of either category were hemmed in by normative gender ideals, which helped compose a distinctive form of what Pooley (2010) described as the "authenticity bind." From showing themselves without makeup (but still "pretty"), to curating aspirational images that allow for an element of "awkward[ness]" in the creator's personal brand, to qualifying lucrative sponsorships as being only with brands they "really love," influencers' projections of authenticity were narrowly defined. That is, these boundary definitions were firmly entrenched in a capitalist economy that privileges creators' "organic" endorsements and expressions of "real beauty." The boundaries around authenticity were therefore similar to what Genz (2015) found in reality TV, with its "limiting script of consumer culture circumscribed by specific gender, class and sexual norms" (p. 547; see also Banet-Weiser, 2012).

The quandary we identified on Instagram is not dissimilar to the double binds that women confront in other male-coded professional contexts, including leadership and politics (Jamieson, 1995), sports (Toffoletti \& Thorpe, 2018), and digital entrepreneurship (Duffy \& Pruchniewska, 2017). In these situations, much like Instagram self-presentation, "no matter what a person does, [they] can't win" (Bateson, Jackson, Haley, \& Weakland, 1956, p. 251). Trapped within this bind, the content creators in our study engaged in strategic acts of revelation and concealment, a delicate form of self-promotion and self-protection that mirrors the activities of women political bloggers, activists, journalists, and academics who have come to anticipate networked hate. Eckert (2018), for instance, chronicled the experiences of female bloggers who believed they should "keep a 'low profile': not posting on hot- 
button topics, emphasizing facts, toning down language, or not promoting their blog to a wider community" (p. 1295). Such experiences, she concludes, have a "chilling effect on expressions."

Our interview data make clear, however, that even sentiments that are less expressly political experience public backlash. This, of course, does not mean such expressions should be not taken seriously; to the contrary, they cast important questions about where to draw the boundaries between harassment and hate and between commenting and criticism (see, for instance, Miltner, 2016). Moreover, the pervasiveness of such backlash on such a "nice" (Lorenz, 2018)—hence feminized-network such as Instagram foregrounds the issue of who gets taken seriously, both by the companies that build and manage these platforms as well as by the public sector that increasingly searches for ways to effectively regulate them.

In the end, it is important to carefully consider the stakes of a social media environment that renders visibility and vulnerability inextricable from one other. In the words of one of our interviewees, “You haven't really made it 'til you've been hated on." That one of the biggest markers of professional success, apparently, is having social media "haters" is quite telling-and worrisome. Such comments not only suggest that online criticism is an inevitable side effect of digital modes of expression, but they also normalize these sorts of expressions within larger, persistent structures of inequality.

Calling attention to how these inequalities are implicated in larger systems of power helps us reckon with the profoundly undemocratic nature of creative work in the early 21st century-from entrenched structural hierarchies that inhibit the role and status of female media workers (Gill, 2014) to patterns of discrimination that sully the tech industry's meritocratic spirit. Given the siren song of visibility-wherein performing our work, and lifestyles for a digital audience is framed as a requirement for success in the neoliberal digital economy-it is all the more urgent to probe the fraught nature of putting oneself out there.

\section{References}

Abidin, C. (2016). Visibility labour: Engaging with influencers' fashion brands and \#OOTD advertorial campaigns on Instagram. Media International Australia, 161(1), 86100. 
Adkins, L. (2001). Cultural feminization: "Money, sex and power" for women. Signs: Journal of Women in Culture and Society, 26(3), 669-695.

Anderson, M. (2015, August 28). Men catch up with women on overall social media use. Pew Research Center. Retrieved from https://www.pewresearch.org/facttank/2015/08/28/men-catch-up-with- women-on-overall-social-media-use/

Banet-Weiser, S. (2012). Authenticity ${ }^{\text {TM }}$ : The politics of ambivalence in a brand culture. New York, NY: New York University Press.

Banet-Weiser, S. (2018). Empowered: Popular feminism and popular misogyny. Durham, NC: Duke University Press.

Bateson, G., Jackson, D. D., Haley, J., \& Weakland, J. (1956). Toward a theory of schizophrenia. Behavioral Science, 1,251-264.

Bishop, S. (2018). Anxiety, panic and self-optimization: Inequalities and the YouTube algorithm. Convergence, 24(1), 69-84.

boyd, d. (2014). It's complicated: The social lives of networked teens. New Haven, CT: Yale University Press.

Carah, N., \& Dobson, A. (2016). Algorithmic hotness: Young women's "promotion” and "reconnaissance" work via social media body images. Social Media + Society, 2(4), 110.

Chess, S., \& Shaw, A. (2015). A conspiracy of fishes, or, how we learned to stop worrying about \#GamerGate and embrace hegemonic masculinity. Journal of Broadcasting \& Electronic Media, 59(1), 208-220.

Cirucci, A. M. (2018). A new women's work: Digital interactions, gender, and social network sites. International Journal of Communication, 12, 2948-2970.

Cotter, K. (2018). Playing the visibility game: How digital influencers and algorithms negotiate influence on Instagram. New Media \& Society, 21(4), 1-19.

Cunningham, S., \& Craig, D. (2017). Being "really real” on YouTube: Authenticity, community and brand culture in social media entertainment. Media International Australia, 164(1), 71-81.

Dobson, A. S. (2016). Postfeminist digital cultures: Femininity, social media, and selfrepresentation. New York, NY: Palgrave Macmillan. 
Dreyfuss, E. (2018, December 18). Twitter is indeed toxic for women, Amnesty Report says. Wired. Retrieved from https://www.wired.com/story/amnesty-report-twitter-abusewomen/

Duffy, B. E. (2017). (Not) getting paid to do what you love: Gender, social media, and aspirational work. New Haven, CT: Yale University Press.

Duffy, B. E., \& Chan, N. K. (2019). "You never really know who's looking": Imagined surveillance across social media platforms. New Media \& Society, 21(1), 119-138.

Duffy, B. E., \& Hund, E. (2015). "Having it all” on social media: Entrepreneurial femininity and self- branding among fashion bloggers. Social Media + Society, 1(2), 111.

Duffy, B., \& Pruchniewska, U. (2017). Gender and self-enterprise in the social media age: A digital double bind. Information, Communication \& Society, 20(6), 843-859.

Duggan, M. (2017). Online harassment 2017. Retrieved from http://www.pewinternet.org/2017/07/11/online-harassment-2017/

Eckert, S. (2018). Fighting for recognition: Online abuse of women bloggers in Germany, Switzerland, the United Kingdom, and the United States. New Media \& Society, 20(4), 1282-1302.

Fleck, A. (2018, July 24). Eight influencers share eight ways to make your Instagram story more engaging. Adweek.Retrieved from https://www.adweek.com/digital/8influencers-share-8-ways- to-make-your-instagram-story-more-engaging/

Fox, J., Cruz, C., \& Lee, J. Y. (2015). Perpetuating online sexism offline: Anonymity, interactivity, and the effects of sexist hashtags on social media. Computers in Human Behavior, 52, 436-442.

Gandini, A. (2016). The reputation economy: Understanding knowledge work in digital society. London, UK: Palgrave Macmillan.

Gehl, R. W. (2011). Ladders, samurai, and blue collars: Personal branding in Web 2.0. First Monday, 16(9). Retrieved from http://firstmonday.org/ojs/index.php/fm/article/view/3579

Genz, S. (2015). My job is me: Postfeminist celebrity culture and the gendering of authenticity. Feminist Media Studies, 15(4), 545-561. 
Gershon, I. (2017). Down and out in the new economy: How people find (or don't find) work today. Chicago, IL: University of Chicago Press.

Gill, R. (2014). Unspeakable inequalities: Post feminism, entrepreneurial subjectivity, and the repudiation of sexism among cultural workers. Social Politics: International Studies in Gender, State \& Society, 21(4), 509-528.

Glaser, B. (1992). Basics of grounded theory analysis: Emergence vs. forcing. Mill Valley, CA: Sociology Press.

Glaser, B., \& Strauss, A. (1967). The discovery of grounded theory: Strategies for qualitative research. Chicago, IL: Aldine Publishing.

Halpern, M., \& Humphreys, L. (2016). Iphoneography as an emergent art world. New Media \& Society, 18(1), 62-81.

Hearn, A. (2010). Structuring feeling: Web 2.0, online ranking and rating, and the digital "reputation" economy. Ephemera, 10(3/4), 421-438.

Hearn, A., \& Schoenhoff, S. (2015). From celebrity to influencer: Tracing the diffusion of celebrity value across the data stream. In P. D. Marshall \& S. Redmond (Eds.), $A$ companion to celebrity (pp. 194-212). Chichester, UK: Wiley.

Hund, E., \& McGuigan, L. (2019). A shoppable life: Performance, selfhood, and influence in the social media storefront. Communication, Culture \& Critique. Retrieved from https://doi.org/10.1093/ccc/tcz004

Humphreys, L. (2018). The qualified self: Social media and the accounting of everyday life. Cambridge, MA: MIT Press.

Jamieson, K. H. (1995). Beyond the double bind: Women and leadership. Oxford, UK: Oxford University Press.

Khamis, S., Ang, L., \& Welling, R. (2017). Self-branding, "micro-celebrity" and the rise of social media influencers. Celebrity Studies, 8(2), 191-208.

Levine, E. (2015). Cupcakes, Pinterest, and ladyporn: Feminized popular culture in the early twenty-first century. Urbana-Champaign, IL: University of Illinois Press.

Lieber, C. (2014, July 30). Inside the Internet's craziest destination for blogger hate. Racked. Retrieved from https://www.racked.com/2014/7/30/7584149/gomi-get-offmy-internets-fashion-bloggers- style-blogs-mom-blogs 
Lorenz, T. (2018, October 15). Instagram has a massive harassment problem. The Atlantic. Retrieved from

https://www.theatlantic.com/technology/archive/2018/10/instagram-hasmassive- harassment-problem/572890/

Marwick, A. E. (2013). Status update: Celebrity, publicity, and branding in the social media age. New Haven, CT: Yale University Press.

Marwick, A. E. (2015). Instafame: Luxury selfies in the attention economy. Public Culture, 27(1), 137-160.

Massanari, A. L. (2018). Rethinking research ethics, power, and the risk of visibility in the era of the "alt-right" gaze. Social Media+ Society, 4(2), 1-9.

McRae, S. (2017). “Get off my Internets”: How anti-fans deconstruct lifestyle bloggers' authenticity work. Persona Studies, 3(1), 13-27.

Miltner, K. (2016, June). Is hateblogging harassment? Examining the boundaries of online antagonism. Paper presented at the International Communication Association, 67th Annual Conference. Fukuoka, Japan.

Nakamura, L. (2015). Afterword: Blaming, shaming, and the feminization of social media. In R. Dubrofsky \& S. A. Magnet (Eds.), Feminist surveillance studies (pp. 221228). Durham, NC: Duke University Press.

Owens, J. (2018, April 11). The age of post-authenticity and the ironic truths of meme culture. Medium. Retrieved from https://medium.com/s/story/post-authenticity-and-thereal-truths-of-meme- culture-f98b24d645a0

Peiss, K. (2011). Hope in a jar: The making of America's beauty culture. Philadelphia, PA: University of Pennsylvania Press.

Piner, C. (2016, July 28). Feminist writer Jessica Valenti takes a break from social media after threat against her daughter. Slate. Retrieved from https://slate.com/humaninterest/2016/07/feminist- writer-jessica-valenti-takes-a-break-from-social-media-afterthreat-against-her-daughter.html

Pooley, J. (2010). The consuming self: From flappers to Facebook. In M. Aronczyk \& D. Powers (Eds.), Blowing up the brand (pp. 71-89). New York, NY: Peter Lang. 
Reagle, J. (2015). Geek policing: Fake geek girls and contested attention. International Journal of Communication, 9, 2862-2880.

Salisbury, M., \& Pooley, J. (2017). The \#nofilter self: The contest for authenticity among social networking sites, 2002-2016. Social Sciences, 6(1), 10.

Salter, A., \& Blodgett, B. (2017). Toxic geek masculinity in media: Sexism, trolling, and identity policing. New York, NY: Palgrave Macmillan.

Schaefer, M. (2012). Return on influence: The revolutionary power of Klout, social scoring, and influence marketing.New York, NY: McGraw-Hill.

Scolere, L., Pruchniewska, U., \& Duffy, B. E. (2018). Constructing the platform-specific self-brand: The labor of social media promotion. Social Media + Society, July-Sept., 111.

Senft, T. M. (2008). Camgirls: Celebrity \& community in the age of social networks. New York, NY: Peter Lang.

Sobieraj, S. (2018). Bitch, slut, skank, cunt: Patterned resistance to women's visibility in digital publics. Information, Communication \& Society, 21(11), 1700-1714.

Thompson, J. B. (2005). The new visibility. Theory, Culture \& Society, 22(6), 31-51.

Toffoletti, K., \& Thorpe, H. (2018). Female athletes' self-representation on social media: A feminist analysis of neoliberal marketing strategies in "economies of visibility." Feminism \& Psychology, 28(1), 11-31.

Turner, F. (2010). From counterculture to cyberculture: Stewart Brand, the Whole Earth Network, and the rise of digital utopianism. Chicago, IL: University of Chicago Press.

Turner, L. (2018, November 9). “Girl, wash your face” is a massive best-seller with a dark message. BuzzFeed. Retrieved from

https://www.buzzfeednews.com/article/lauraturner/rachel-hollis-girl- wash-your-faceself-help-book

Usher, N., Holcomb, J., \& Littman, J. (2018). Twitter makes it worse: Political journalists, gendered echo chambers, and the amplification of gender bias. The International Journal of Press/Politics, 23(3), 324-344. 
van Dijck, J. (2013). "You have one identity": Performing the self on Facebook and LinkedIn. Media, Culture \& Society, 35(2), 199-215. doi:10.1177/0163443712468605

Veletsianos, G., Houlden, S., Hodson, J., \& Gosse, C. (2018). Women scholars' experiences with online harassment and abuse: Self-protection, resistance, acceptance, and self-blame. New Media \& Society, 20(12), 4689-4708.

Vera-Gray, F. (2017). "Talk about a cunt with too much idle time”: Trolling feminist research. Feminist Review, 115, 61-78.

Wissinger, E. (2015). This year's model: Fashion, media, and the making of glamour. New York, NY: New York University Press.

\section{REPRINT}

"Gendered Visibility on Social Media: Navigating_Instagram's Authenticity Bind" (Brooke Erin Duffy and Emily Hund, International Journal of Communication 13, September 2019)

OPENLY LICENSED

\section{Footnotes}

1. We would like to extend our gratitude to Rebecca Howard-Cooper, Jenny Lei, Gabrielle Lynn, and Karly Krasnow for their invaluable research assistance; the members of Cornell University's New Media \& Society Group for their thoughtful feedback; and the two anonymous reviewers for their productive recommendations. $\subseteq$

2. Peiss' (2011) social history of the American cosmetics industry details Victorianera concerns about "painted ladies," a euphemism for prostitutes. A woman's use of makeup was initially cast as a symbol of her immorality. $\subseteq$

3. Anonymity is a vexed concept for Internet researchers (Massanari, 2018), and some of our interviewees requested that we use their names in hopes of bringing attention to their sites. Yet, given that the outcome of the study was not known at the time of research, we opted to use pseudonyms to avoid potentially reproducing online criticism. 